\title{
Buji Ateşlemeli Motorlarda Kullanılan n-Propanol ve izo-Propanol/Benzin Yakıt Karışımlarının Performans ve Emisyonlara Etkisi
}

\author{
Doğan ŞİMŞEK ${ }^{1}$, Niyazi Yılmaz ÇOLAK ${ }^{1 *}$, Faruk ORAL ${ }^{2}$ \\ ${ }^{1}$ Bitlis Eren Üniversitesi, Teknik Bilimler Meslek Yüksekokulu, Bitlis, Türkiye \\ ${ }^{2}$ Bitlis Eren Üniversitesi, Mühendislik-Mimarlık Fakültesi, Bitlis, Türkiye
}

\begin{abstract}
Özet
$\mathrm{Bu}$ çalışmada buji ateşlemeli bir motorda n-propanol ve izo-propanol alkolleri kullanımının motor performans ve emisyonlarına etkisi incelenmiştir. Deneylerde B100 (\%100 benzin) $20 \mathrm{n}$-pro (\%80 benzin $+\% 20$ n-propanol) ve 20 izo-pro (\%80 benzin+\%20 izo-propanol) yakıt karışımları kullanılmıştır. Deneyler motor tam gaz konumunda, altı farklı motor devrinde (yükünde) (1500-4000 d/dk) yapılmıştır. Performans sonuçlarına göre, izo-propanol alkolü ilavesi ile motor momentinde ve motor gücünde önemli bir değişiklik görülmemiştir. Fakat özgül yakıt tüketimi izo-propanol alkol kullanılmasıyla \%2,23 oranında artmıştır. Emisyon sonuçlarına göre, $\mathrm{HC}$ ve CO emisyonları alkol ilavesi ile birlikte sırası ile yaklaşık \%10,52 ve \%4,41 azalmıştır. Öte yandan $\mathrm{CO}_{2}$ ve $\mathrm{NO}_{\mathrm{X}}$ emisyonları sırası ile yaklaşık $\% 17,38$ ve $\% 15,24$ oranında artmıştır.
\end{abstract}

Anahtar kelimeler: Buji ateşlemeli motor, n-propanol, izo-propanol, motor performansı, yakıt karışımı.

\section{The Effect on Performance and Emissions the Spark Ignition Engines of n-propanol and iso-propanol/Gasoline Fuel Blends}

\begin{abstract}
In this study, the effect of the usage of n-propanol and iso-propanol alcohols in a spark ignition engine on engine performance and emissions is investigated. Fuel mixtures of B100 (100\% gasoline), 20 n-pro (80\% gasoline + $20 \%$ n-propanol) and 20 iso-pro ( $80 \%$ gasoline $+20 \%$ iso-propanol) are used in the experiments. The tests are carried out at six different engine speeds $(1500-4000 \mathrm{~d} / \mathrm{min})$ in full-throttle position. The results show that the addition of iso-propanol alcohol resulted in a $2.23 \%$ increase in the specific fuel consumption without significant changes in motor momentum and power. In the emission results, it is determined that $\mathrm{HC}$ and $\mathrm{CO}$ emissions decreased by $10.42 \%$ and $4.41 \%$ respectively while CO2 and NOx emissions increased by $17.38 \%$ and $15.24 \%$ respectively.
\end{abstract}

Keywords: Spark ignition engine, n-propanol, iso-propanol, engine performance, fuel blends.

\section{Giriş}

Geleneksel fosil kökenli yakıtların, rezervlerinin sınırlı olması ve enerji bağımlılı̆̆ının azaltılması yönündeki girişimler yenilenebilir enerji kaynaklarının daha etkin olarak kullanılması gerekliliğini açığa çıkarmıştır [1]. Bunun yanı sıra artan çevre bilinci ve emisyon değerlerindeki küresel sınırlamalarda bu gerekliliği desteklemektedir. Özellikle içten yanmalı motorlarda çevre kirliliği açısından, biyokütle yakıtları önemli bir alternatif yakıt olarak görülmektedir [2,3]. Sıkıştırma ile ateşlemeli motorlarda bitkisel kökenli yağlar (biyodizel) iyi bir alternatif yakıt olarak görülürken, buji ateşlemeli motorlarda ise alkoller iyi bir alternatif yakıt olarak görülmektedir. Biyokimyasal işlemlerle elde edilen alkoller, yüksek oksijen içeriği ile temiz ve sürdürülebilir bir alternatif yakıt olma potansiyeline sahiptirler [4].

*Sorumlu yazar: nycolak@beu.edu.tr

Geliş Tarihi: 10.06.2018, Kabul Tarihi: 14.11.2018 
Son zamanlarda biyo-etanol ve bununla birlikte biyo-bütanol gibi biyo-alkollerin kullanılmasına yönelik yoğun ilgi bulunmaktadır [5,6]. Literatürde yapılan birçok çalışma arasında etanol ve metanol buji ateşlemeli motorlar için iyi bir alternatif yakıt olarak görülmektedir [7,8]. Öte yandan, doymuş C3 alkolleri (n-propanol ve izo-propanol), etanol ve metanol ile karşılaştırıldığında daha iyi bir enerji yoğunluğuna ve düşük afiniteye sahiptir [1]. Propanol, öncelikle en uygun maliyetli olan okso sentezi ile petrokimyasallardan üretilmektedir [9]. Ancak fosil yakıt rezervlerinin tükenmesi endişeleri nedeniyle, bu alkolü üretmek için sürdürülebilir yöntemler geliştirilmiştir. Shen ve Liao [10], Atsumi ve Liao [11], Escherichia coli isimli bir bakteri türü kullanarak bitkisel kökenli glikozdan n-propanol üretme teknikleri geliştirmişlerdir. Bunun yanı sıra propanol, biyokütle veya evsel katı atıklar gibi stoklardan üretilebilmektedir [12]. Bu nedenle, C3 (doymuş) alkolleri, düşük moleküler ağırlıklı alkollere potansiyel bir alternatif olarak artan bir ilgiye sahiptir. Keskin ve Gürü [13], dört zamanlı buji ateşlemeli bir motorda belirli oranlarda benzin-etanol ve benzin-propanol yakıt karışımlarının egzoz ve gürültü emisyonları üzerine etkisini araştırdıkları çalışmada, izo-propanol ilave edilen yakıtların kullanılması ile $\mathrm{HC}$ ve $\mathrm{CO}$ emisyonlarının arttığını, $\mathrm{NO}_{\mathrm{X}}$ ve $\mathrm{CO}_{2}$ emisyonlarının azaldığını belirtmişlerdir. Altun vd. tarafından yapılan çalışmada [14], buji ateşlemeli bir motorda benzin-izopropanol yakıt karışımlarının kullanılmasının egzoz emisyonları üzerine etkisini incelemişlerdir. Elde ettikleri sonuçlarda, Karbonmonoksit (CO) ve Hidrokarbon (HC) emisyonları azalırken, karbondioksit $\left(\mathrm{CO}_{2}\right)$ emisyonlarının arttı̆̆ını belirtmişlerdir. Mourad ve Mahmoud [15]tarafindan yapılan çalışmada ise, yakıt ekonomisinin yaklaşı \% 2,84 oranında arttı̆̆ , egzoz emisyonlarında iyileşmenin olduğu, özellikle HC ve CO emisyonlarında sırası ile \%14,18 ve \%10,87 oranında azaldığ 1 belirtilmektedir. Yapılan bu çalışmada, buji ateşlemeli bir motorda, benzin içerisine belirli bir oranda ilave edilen propanol izomerlerinin, motor performans ve emisyonlarına etkisinin incelenmesi ve ilgili alandaki araştırmalara katkı sağlaması amaçlanmıştır.

\section{Materyal ve Metot}

Yapılan bu çalışmada, kullanılan benzin piyasadan, n-Propanol $\left(\mathrm{C}_{3} \mathrm{H}_{8} \mathrm{OH}\right) \% 99$ saflıkta, iso-Propanol $\left(\mathrm{C}_{3} \mathrm{H}_{8} \mathrm{OH}\right) \% 99,5$ saflıkta Sigma-Aldrich firmasından temin edilmiştir. Deneylerde kullanılan yakıtların fiziksel özellikleri Tablo 1'de verilmiştir.

Tablo 1. Test yakıtlarının fiziksel özellikleri

\begin{tabular}{lccc}
\hline Yakıt Özelliği & Benzin & n-Propanol & izo-Propanol \\
\cline { 2 - 4 } Formül & $\mathrm{C}_{8} \mathrm{H}_{18}$ & $\mathrm{C}_{3} \mathrm{H}_{8} \mathrm{OH}$ & $\mathrm{C}_{3} \mathrm{H}_{8} \mathrm{OH}$ \\
Moleküler Ăğırlı̆̆ı (kg/kmol) & 114.18 & 60,1 & 60,10 \\
Alt Isıl Değer (MJ/kg) & 44 & 29,81 & 32,94 \\
Stokiyometrik Hava /Yakıt Oranı & 14,60 & 10,28 & 10,28 \\
Kendinden Tutuşma Sıcaklığı $\left({ }^{\circ} \mathbf{C}\right)$ & 257 & 380 & 380 \\
Buharlaşma Isısı (kJ/kg) & 225 & 585 & 761 \\
Araştırma Oktan Sayısı & 95 & 112 & 112,5 \\
Motor Oktan Sayısı & 85 & ---- & ---- \\
Yoğunluk (kg/m $\left.{ }^{3}\right)$ & 765 & 804 & 785 \\
\hline
\end{tabular}

Deneylerde tek silindirli, buji ateşlemeli, hava soğutmalı ATIMAX AG 210 E motor kullanılmıştır. Testlere başlanmadan önce motor, katalog değerlerinde belirtilen egzoz emisyon verileri kullanılarak karbüratör ayarlanmıştır. Bütün test şartlarında konik uçlu ayar vidası kullanılarak hava fazlalık katsayısı (HFK - $\lambda=1$ ) olarak ayarlanmıştır. Kullanılan bütün yakıt türlerinde ayar işlemi tekrarlanmıştır. Deneylere motor çalışma sıcaklığına ulaştığında başlanmıştır. Deneylerde altı farklı devir aralığ 1 (1500-4000 d/dk) kullanılmıştır. Deneylerde kullanılan motorun teknik özellikleri Tablo 2 'de verilmiş̧ir. Motor performans test stand1, Şekil 1'de şematik olarak verilmiştir. Test sisteminde 26 $\mathrm{kW}, 80 \mathrm{Nm}$ tork ve max $5000 \mathrm{rpm}$ hızında elektrikli dinamometre kullanılmaktadır. Test sisteminde yakıt tüketimi, motor momenti ve motor gücü verileri anlık olarak, kullanılan ara yüz programı ile dijital olarak kaydedilmiştir. 
Tablo 2. Test motorunun özellikleri

\begin{tabular}{ll}
\hline Marka & Atimax 210 E \\
Motor Tipi & Dört Zamanlı, Tek Silindirli \\
Motor Hacmi $\left(\mathbf{c m}^{\mathbf{3}}\right)$ & 196 \\
Sıkıştırma Oranı & $8,5 / 1$ \\
Maksimum Hız (rpm) & 3600 \\
Ateşleme Sistem Tipi & Transistörlü Bobin \\
Yakıt Sistemi & Karbüratör \\
Soğutma Sistemi & Hava Soğutmalı \\
\hline
\end{tabular}

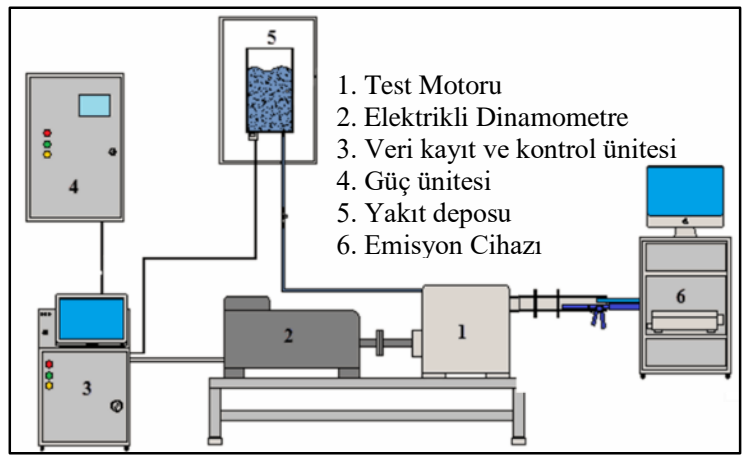

Şekil 1. Deney düzeneği şematik görünümü

Emisyon ölçümleri belirlenen motor devirlerinde ölçülmüştür. Emisyon ölçümlerinde Mobydic5000 gaz analiz cihazı kullanılmıştır. Kullanılan emisyon cihazı teknik özellikleri Tablo 3'de verilmiştir.

\begin{tabular}{ll} 
Tablo 3. Egzoz gaz analiz cihazının özellikleri \\
\hline \multicolumn{2}{c}{ MOBYDIC 5000 GAZ ANALİ CİHAZI } \\
\hline CO \% Hac. & $0-10$ \\
CO2 \% Hac. & $0-20$ \\
HC ppm & $0-20000$ \\
O $_{2} \%$ Hac. & $0-21$ \\
NOx ppm & $0-5000$ \\
Lambda & $0-5$ \\
\hline
\end{tabular}

\section{Bulgular ve Tartışma}

Benzin yakıtına ilave edilen farklı alkol türlerinin motor momentine etkisi Şekil 2'de verilmiştir.

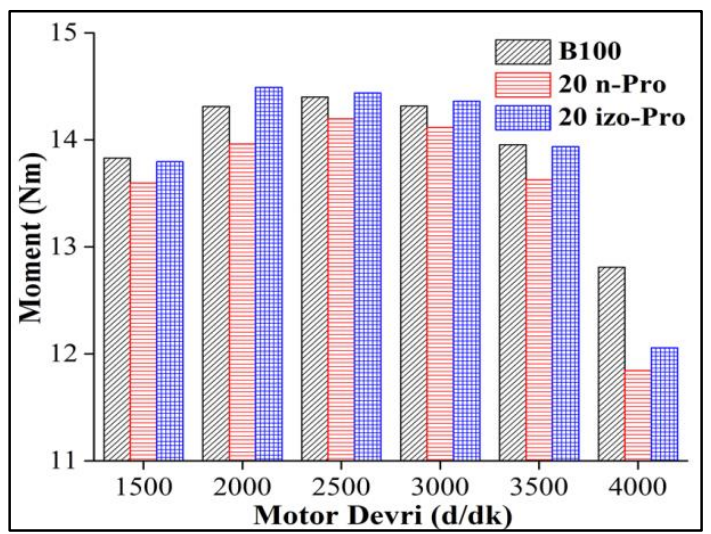

Şekil 2. Benzin yakıtına ilave edilen farklı alkol türlerinin motor momentine etkisi 
Şekil 2'de verilen farklı yakıt türlerinin motor momentine etkisi incelendiğinde, maksimum motor momentinin benzin yakıtı ile $2500 \mathrm{~d} / \mathrm{dk}$ motor devrinde olduğu görülmektedir. Standart benzin yakıtı ile maksimum motor momenti $14,39 \mathrm{Nm}, \% 20 \mathrm{n}$-Propanol ilave edilen yakıt ile $14,19 \mathrm{Nm}$ ve $\% 20$ izo-Propanol ilave edilen yakıt karışımı ile 14,43 Nm olarak elde edilmiştir. Benzin içerisine izopropanol alkolü ilavesi ile bütün motor devirlerinde motor momentinde azda olsa bir artışın olduğu görülmektedir. Bu durum yanma hızı ile açıklanabilir. Çünkü yavaş yanma ile daha fazla faydalı enerji elde edilebilmektedir [16]. Daha önce yapılan bir çalışmada izo-propanol/hava alevlerinin npropanol/hava alevlerinden sürekli olarak $3,5-5 \mathrm{~cm} / \mathrm{sn}$ daha düşük olduğu belirtilmiştir [1]. Bununla birlikte n-Propanol alkolü ilavesi ile motor momentinde azalmanın olduğu görülmektedir. Motor momentindeki bu azalma, silindir içerisine alınan hava yakıt karışımının alt 1sıl değerinin düşük olmasından (kullanılan alkollerin alt 1sıl değerlerinin düşük olması) kaynaklanmaktadır. Daha önce yapılan bazı çalışmalarda benzer sonuçlar rapor edilmiştir $[2,7,8,16]$. Benzin yakıtına ilave edilen farklı alkol türlerinin ÖYT'ne (Özgül Yakıt Tüketimi) etkisi Şekil 3'de verilmiştir.

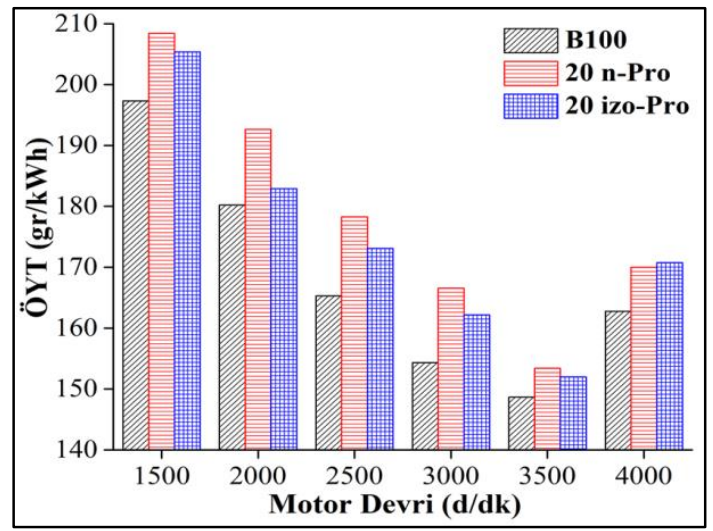

Şekil 3. Benzin yakıtına ilave edilen farklı alkol türlerinin ÖYT'ne etkisi

Şekil 3'de verilen ÖYT değişimi incelendiğinde artan motor devri ile ÖYT'nin azaldı̆̆ minimum ÖYT'nin $3500 \mathrm{~d} / \mathrm{dk}$ motor devrinde elde edildiği anlaşılmaktadır. Minimum ÖYT benzin yakıtı kullanılması ile 148,652 gr/kWh, \%20 n-propanol ilave edilen yakıt kullanılması ile 153,412 $\mathrm{gr} / \mathrm{kWh}$ ve \%20 izo-propanol ilave edilen yakıt kullanılması ile 151,975 gr/kWh olarak elde edilmiştir. ÖYT benzin içerisine ilave edilen alkol ile arttı̆̆ anlaşılmaktadır. Bu durum beklenen bir sonuçtur, çünkü benzin içerisine alt ısıl değeri düşük alkol ilavesi ile silindir içerisine alınan yakıt hava karışımının alt ısıl değerinin düşmesine ve aynı enerjinin elde edilebilmesi için silindir içerisine daha fazla yakıt gönderilmesi ÖYT’nin artmasına neden olmaktadır. Daha önce yapılan çalışmalarda benzer sonuçlar elde edilmiştir [15,17]. Motor moment grafiği incelendiğinde 20 izo-Propanol yakıtı ile daha düşük ÖYT elde edilmesi beklenmektedir. Ancak kullanılan alkollerin buharlaşma ısısının yüksek olması ile silindir içerisine alınan karışımın soğutma etkisi ile belirli bir orana kadar azda olsa bir miktar güç artışı sağlamaktadır [18]. Ayrıca testler esnasında kullanılan HFK $(\lambda=1)$ ile hava yakıt oranı sabit tutulmaya çalışılmıştır. Bu nedenle, Tablo 1'de verilen yakıtların özelliklerinden de anlaşıldığ 1 üzere kullanılan alkollerin stokiyometrik hava yakıt oranları benzin yakıtının stokiyometrik hava yakıt oranından düşüktür. Bu oranda, sabit gaz kelebek açıklığında, aynı hava miktarının emilmesi ile içeriye giren yakıt miktarının daha fazla olması anlamına gelmektedir. Bu durum, alkol ilaveli yakıtların kullanılması ile ÖYT’nin artmasında diğer bir neden olarak söylenebilir. Benzin yakıtına ilave edilen farklı alkol türlerinin Hidrokarbon (HC) emisyonlarına etkisi Şekil 4 'te verilmiştir. 


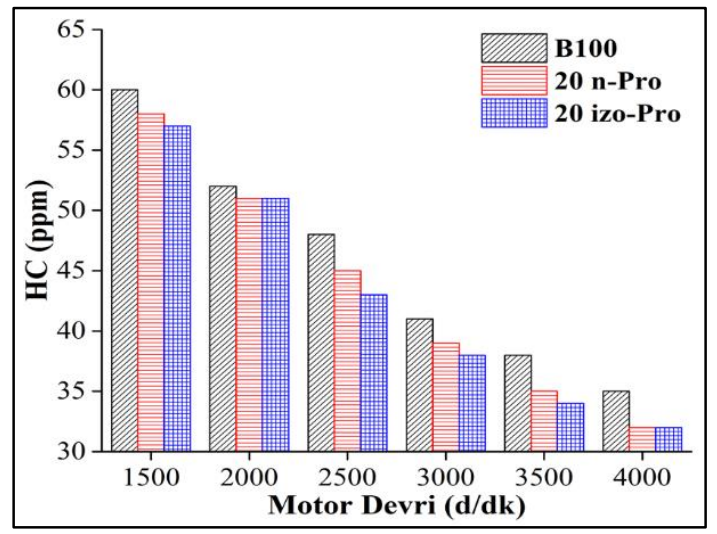

Şekil 4. Benzin yakıtına ilave edilen farklı alkol türlerinin HC emisyonları'na etkisi

Şekil 4'te verilen farklı alkol türlerinin $\mathrm{HC}$ emisyonlarına etkisi incelendiğinde, artan motor devri ile $\mathrm{HC}$ emisyonlarının azaldığı görülmektedir. Bununla birlikte benzin çerisine ilave edilen propanol alkolü ile HC emisyonları azalmaktadır. Bütün motor devirlerinde en düşük HC emisyonu izopropanol alkolü ilave edilen yakıt türünde elde edilmiştir. Minimum ÖYT elde edildiği $3500 \mathrm{~d} / \mathrm{dk}$ motor devrinde (elde edilen maksimum motor güç devri) benzin yakıtı kullanılması ile 38 ppm, \%20 npropanol ilave edilen yakıt ile $35 \mathrm{ppm}$ ve $\% 20$ izo propanol ilave edilen yakıt kullanılmasında ise 34 ppm olarak elde edilmiştir. Benzin içerisine propanol alkolü ilave edilmesi ve propanol alkolünün düşük karbon ve yüksek oksijen muhteviyatı $\mathrm{HC}$ emsiyonlarında bu azalmanın temel nedenidir. Çünkü yanma işleminde oksijen miktarının fazla olması yanma odasında gerçekleşen reaksiyonların daha verimli gerçekleşmesini sağlar [15]. Bununla birlikte alkol yakıtları kullanılması durumunda motor avansının uyumsuz olması yanma periyodunun gecikmesine ve egzoz zamanında da devam etmesi ile HC emisyonlarının azalmasına neden olduğu söylenebilir. Şekil 6.b'de verilen egzoz gaz sıcaklığındaki artış bu durumu desteklemektedir. Topgül vd. [19] tarafından yapılan bir çalışmada, benzin alkol karışımı ile çalışan bir motorun ateşleme zamanının artırılması ile yanma periyodunun arttığı ve 1sı döngüsünün daha verimli kullanılması ile motor momenti artarken egzoz gaz sıcaklığında ise azalmanın olduğu belirtmişlerdir. Benzin yakıtına ilave edilen farklı alkol türlerinin Karbonmonoksit (CO) ve Karbondioksit $\left(\mathrm{CO}_{2}\right)$ emisyonlarına etkisi Şekil 5'de verilmiştir.


Şekil 5. Benzin yakıtına ilave edilen farklı alkol türlerinin a) $\mathrm{CO}$ ve b) $\mathrm{CO}_{2}$ emisyonlarına etkisi

Şekil 5.a'da verilen farklı alkol türlerinin CO emisyonlarına etkisi incelendiğinde, artan motor devri ile CO emisyonlarının azaldığ 1 görülmektedir. Bununla birlikte benzin içerisine ilave edilen propanol alkolü ile $\mathrm{CO}$ emisyonları azalmaktadır. Bütün motor devirlerinde en düşük $\mathrm{CO}$ emisyonu izopropanol alkolü ilave edilen yakıt türünde elde edilmiştir. Minimum ÖYT'nin elde edildiği motor devrinde (3500 d/dk) benzin yakıtı kullanılması ile \%1,81- \%20 n-propanol ilave edilen yakıt ile \%1,74 ve \%20 izo propanol ilave edilen yakıt kullanılmasında ise \%1,73 olarak elde edilmiştir. Benzin içerisine ilave edilen izo-propanol alkolü ile silindir içerisinde artan oksijen miktarı yanma verimini arttırmakta ve CO emisyonlarında azalmaya neden olmaktadır. Daha önce yapılan çalışmalarda benzer sonuçlar elde edilmiştir $[13,15,20]$. Şekil 5.b'de verilen $\mathrm{CO}_{2}$ emisyonu değişimleri incelendiğinde, benzin 
çerisine ilave edilen propanol alkolü ile $\mathrm{CO}_{2}$ emisyonlarının arttığı görülmektedir. Bütün motor devirlerinde en düşük $\mathrm{CO}_{2}$ emisyonu benzin yakıtı kullanılması ile elde edilmiştir. Minimum ÖYT'nin elde edildiği motor devrinde $(3500 \mathrm{~d} / \mathrm{dk})$ benzin yakıtı kullanılması ile \%8,63, \%20 n-propanol ilave edilen yakıt ile $\% 10,09$ ve $\% 20$ izo propanol ilave edilen yakıt kullanılmasında ise $\% 10,13$ olarak elde edilmiştir. Bir hidrokarbonun yanması sırasında $\mathrm{CO}, \mathrm{CO}_{2}, \mathrm{CH}_{4}$ ve metan olmayan $\mathrm{HC}$ şeklinde karbonlu gazlar açığa çıkar ve karbonun çoğu $\mathrm{CO}_{2}$ gazı halinde salınır [21]. Yanma veriminin yüksek olması ile karbon dönüşümünün \% 90'dan fazlası $\mathrm{CO}_{2}$ ürünü ile sonuçlanır. Benzin yakıtı içerisine ilave edilen alkolün oksijen muhteviyatı yanma verimini artırmakta ve dolayısıyla $\mathrm{CO}_{2}$ emisyonu artmaktadır. Şekil 5.a'da verilen $\mathrm{CO}$ emisyon değişimi bu durumu desteklemektedir. Nitekim $\mathrm{CO}_{2}$ emisyonu değişimi nispi yakıt hava karışımına ve CO konsantrasyonuna bağlıdır [22]. Benzin yakıtına ilave edilen farklı alkol türlerinin azotoksit $\left(\mathrm{NO}_{\mathrm{x}}\right)$ emisyonlarına ve egzoz gaz sıcaklıklarına etkisi Şekil 6'da verilmiştir.
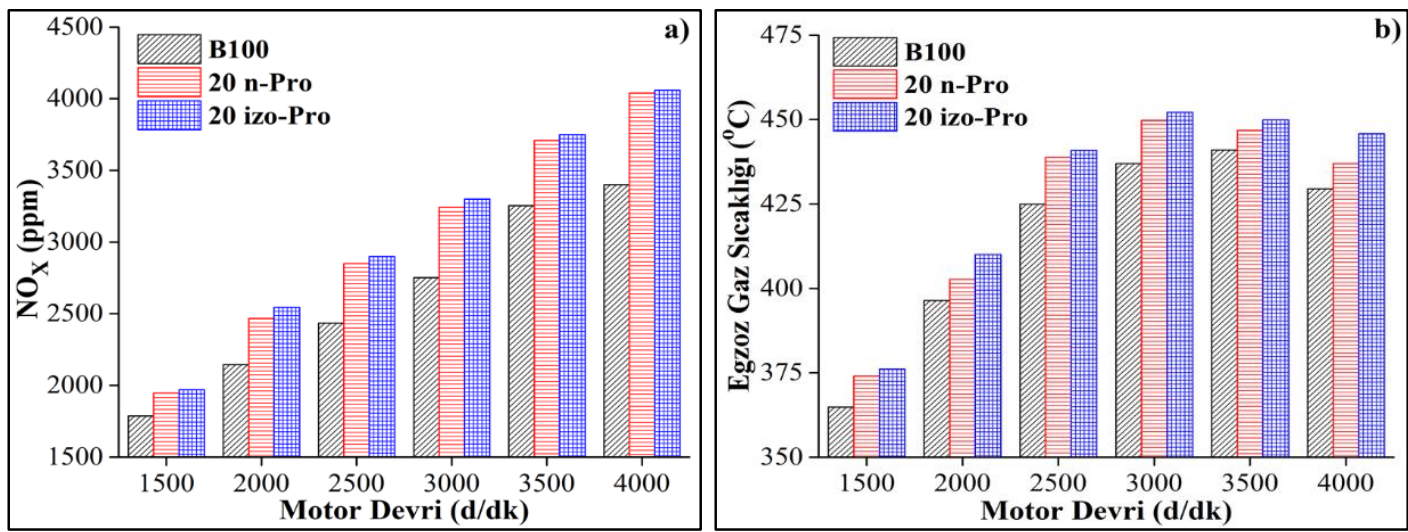

Şekil 6. Benzin yakıtına ilave edilen farklı alkol türlerinin a) Azotoksit $\left(\mathrm{NO}_{\mathrm{X}}\right)$ emisyonlarına ve b) Egzoz gaz sicaklıklarına etkisi

Şekil 6.a'da verilen $\mathrm{NO}_{\mathrm{x}}$ emisyon değişim grafiği incelendiğinde, minimum ÖYT'nin elde edildiği motor devrinde $(3500 \mathrm{~d} / \mathrm{dk})$ maksimum $\mathrm{NO}_{\mathrm{X}}$ emisyonu \%20 izo-propanol ilave edilen yakıt ile $3750 \mathrm{ppm}$ olarak elde edilmiştir. Benzin yakıtı kullanılması ile aynı motor devrinde $3254 \mathrm{ppm}$ ve $\% 20$ n-propanol ilave edilen yakıt 3709 ppm olarak elde edilmiştir. $\mathrm{NO}_{\mathrm{x}}$ emisyonu oluşumu silindir içi sıcaklığa bağlı olarak değişmektedir [23]. Artan sıcaklık ile $\mathrm{N}_{2}$ gazlarının oksidasyonuda artmaktadır. Keskin ve Gürü [13] tarafından yapılan bir çalışmada NO emisyonunda artış olduğu bu artışın yanma işlemi sırasında $\mathrm{N}_{2}$ gazlarının oksidasyonunu arttıran karışım yakıtlar içerisindeki oksijen içeriğine bağlı olabileceğini belirtmişlerdir. Bunun yanı sıra, yine Keskin ve Gürü aynı çalışmalarında literatürde benzer çalışmalarda değişik sonuçlarında elde edildiğini belirtmişlerdir [13]. Şekil 6.b'de verilen egzoz gaz sıcaklığı sonuçları bu durumu desteklemektedir. Yusoff vd. [24], yaptıkları bir çalışmada alkol ilave edilen yakıtlarda daha yüksek NO emisyonları elde ettiklerini ve bu durumun egzoz gaz sıcaklığı ile ilişkili olduğunu belirtmişlerdir. Şekil 6.b'de verilen egzoz gaz sıcaklığı sonuçları beklenmeyen bir durumdur. Silindir içerisine alınan taze dolgunun buharlaşma 1sısı yüksek olan alkol muhteviyatı ile soğutma etkisi yapmaktadır. Bu nedenle egzoz gaz sıcaklığının azalması beklenmektedir. Egzoz gaz sıcaklığındaki bu artışın yanma periyodunun egzoz zamanına gecikmesinden kaynaklandığı düşünülmektedir. Bununla ilgili, yapılan bir çalışmada ateşleme avansının artması ile egzoz gaz sıcaklığının azaldığı belirtilmektedir [19].

\section{Sonuç ve Öneriler}

Buji ateşlemeli bir motorda benzin yakıtına \%20 n-propanol ve izo-propanol ilavesinin motor performansı ve egzoz emisyonları üzerine etkisinin araştırıldığı bu çalışmada elde edilen sonuçlar aşağı 1 a verilmiştir.

Maksimum motor momenti $2500 \mathrm{~d} / \mathrm{dk}$ benzin yakıtı ile elde edilmiştir. Benzin yakıtına göre, $\% 20$ n-propanol kullanılması ile motor momentinde yaklaşı \% $1,38, \% 20$ izo-propanol ilave edilmesi ile yaklaşık \%0,34 oranında bir azalma olduğu belirlenmiştir. 
Minimum ÖYT ve motor gücü, benzin yakıtı ile $3500 \mathrm{~d} / \mathrm{dk}$ motor hızında elde edilmiştir. Benzin yakıtına göre, \% 20 n-propanol ilave edilmesi ile yaklaşık olarak \%3.20, \%20 izo-propanol ilave edilmesi ile yaklaşık olarak \% 2,23 oranında bir artışın olduğu belirlenmiştir.

Maksimum motor gücünün elde edildiği motor devrinde, minimum CO emisyonu \%20 izopropanol ilave edilen yakıt ile elde edilmiştir. Benzin yakıtına göre, \%20 n-propanol ilave edilen yakıt kullanılması ile yaklaşık olarak \%3,86, \% 20 izo propanol ilave edilen yakıt kullanılması ile yaklaşık olarak \% 4,41 oranında bir azalmanın olduğu belirlenmiştir.

Maksimum motor gücünün elde edildiği motor devrinde, minimum $\mathrm{CO}_{2}$ emisyonu benzin yakıt1 ile elde edilmiştir. \%20 n-propanol ilave edilen yakıt kullanılması ile yaklaşık \%16,91, \%20 izopropanol ilave edilen yakıt karışımı ile yaklaşık olarak \%17,38 oranında bir artışın olduğu belirlenmiştir. Maksimum motor gücünün elde edildiği motor devrinde, minimum $\mathrm{NO}_{\mathrm{x}}$ emisyonu benzin yakıtı ile elde edilmiştir. \%20 n-propanol ilave edilen yakıt kullanılması ile yaklaşık olarak \%13,98, \% 20 izo-propanol ilave edilen yakıt kullanılması ile yaklaşı olarak \%15,24 oranında bir artışın olduğu belirlenmiştir.

\section{Kaynaklar}

[1] Veloo P S., Egolfopoulos F.N. 2011. Studies of n-propanol, iso-propanol, and propane flames. Combustion and Flame, 158 (3): 501-510.

[2] Li Y., Meng L., Nithyanandan K., Lee T.H., Lin Y., Lee C.F., Liao S. 2016. Combustion, performance and emissions characteristics of a spark-ignition engine fueled with isopropanolnbutanol-ethanol and gasoline blends. Fuel, 184: 864-872.

[3] Balki, M. K., Sayin, C., Canakci, M. 2014. The effect of different alcohol fuels on the performance, emission and combustion characteristics of a gasoline engine. Fuel, 115: 901-906.

[4] Beatrice C., Bertoli C., Giacomo N.D. 1998. New findings on combustion behavior of oxygenated synthetic diesel fuels. Combustion science and technology, 137 (1-6): 31-50

[5] Tehrani, N. F., Aznar, J. S., Kiros, Y. 2015. Coffee extract residue for production of ethanol and activated carbons. Journal of Cleaner Production, 91: 64-70.

[6] Bhutto A.W., Harijan K., Qureshi K., Bazmi A.A., Bahadori A. 2015. Perspectives for the production of ethanol from lignocellulosic feedstock-A case study. Journal of Cleaner Production, 95: 184-193.

[7] Elfasakhany A. 2016. Engine performance evaluation and pollutant emissions analysis using ternary bio-ethanol-iso-butanol-gasoline blends in gasoline engines. Journal of cleaner production, 139: 1057-1067.

[8] Çelik M.B., Özdalyan B., Alkan F. 2011. The use of pure methanol as fuel at high compression ratio in a single cylinder gasoline engine. Fuel, 90 (4):1591-1598.

[9] Cornils B. 2004. Handbook of Commercial Catalysts. Heterogeneous Catalysts. By Howard F. Rase. 2324-2325,

[10] Shen, C.R., Liao, J.C. 2008. Metabolic engineering of Escherichia coli for 1-butanol and 1-propanol production via the keto-acid pathways. Metabolic engineering, 10 (6): 312-320.

[11] Atsumi, S., Liao, J. C. 2008. Directed evolution of Methanococcus jannaschii citramalate synthase for biosynthesis of 1-propanol and 1-butanol by Escherichia coli. Applied and environmental microbiology, 74 (24): 7802-7808.

[12] Liu K., Atiyeh H.K., Stevenson B.S., Tanner R.S., Wilkins M.R., Huhnke R.L. 2014. Continuous Syngas Fermentation for the Production of Ethanol, n-propanol and n-butanol. Bioresource Technology, 151: 69-77

[13] Keskin A., Gürü M. 2011. The effects of ethanol and propanol additions into unleaded gasoline on exhaust and noise emissions of a spark ignition engine. Energy Sources, Part A: Recovery, Utilization, and Environmental Effects, 33 (23): 2194-2205

[14] Altun Ş., Öner C., Firat M. 2010. Exhaust emıssions from a spark-1gnitıon engine operatıng on 1sopropanol and unleaded gasolıne blends. Technology, 13 (3): 183-188.

[15] Mourad M., Mahmoud K.R. 2018. Performance investigation of passenger vehicle fueled by propanol/gasoline blend according to a city driving cycle. Energy, 149: 741-749.

[16] Li Y., Meng L., Nithyanandan K., Lee T.H., Lin Y., Chia-fon F.L., Liao S. 2016. Combustion, performance and emissions characteristics of a spark-ignition engine fueled with isopropanol-nbutanol-ethanol and gasoline blends. Fuel, 184: 864-872. 
[17] Masum B.M., Masjuki H.H., Kalam M.A., Palash, S.M., Habibullah, M. 2015. Effect of alcoholgasoline blends optimization on fuel properties, performance and emissions of a SI engine. Journal of Cleaner Production, 86: 230-237.

[18] Celik, M.B. 2008. Experimental determination of suitable ethanol-gasoline blend rate at high compression ratio for gasoline engine. Applied Thermal Engineering, 28 (5-6): 396-404

[19] Topgül, T., Yücesu, H. S., Cinar, C., \& Koca, A. (2006). The effects of ethanol-unleaded gasoline blends and ignition timing on engine performance and exhaust emissions. Renewable energy, 31 (15): 2534-2542.

[20] Gravalos I., Moshou D., Gialamas T., Xyradakis P., Kateris D., Tsiropoulos Z. 2013. Emissions characteristics of spark ignition engine operating on lower-higher molecular mass alcohol blended gasoline fuels. Renewable Energy, 50: 27-32

[21] Ward D.E. 1993. Trace gasses and particulate matter from fires-a review. In Background Paper for Proceedings of the Victoria Falls Workshop, June (Vol. 2).

[22] Wu C.W., Chen R.H., Pu J.Y., Lin T.H. 2004. The influence of air-fuel ratio on engine performance and pollutant emission of an SI engine using ethanol-gasoline-blended fuels. Atmospheric Environment, 38 (40): 7093-7100.

[23] Çelik, M. B., Çolak, A. 2008. Buji Ateşlemeli Bir Motorda Alternatif Yakıt Olarak Saf Etanolün Kullanılması. Gazi Üniversitesi, Mühendislik Ve Mimarlık Fakültesi Dergisi, 23 (3): 619-626.

[24] Yusoff M.N.A.M., Zulkifli N.W.M., Masjuki H.H., Harith M.H., Syahir A.Z., Kalam M.A., Mansor M.F., Azham A., Khuong L.S. 2017. Performance and emission characteristics of a spark ignition engine fuelled with butanol isomer-gasoline blends. Transportation Research Part D: Transport and Environment, 57: 23-38. 